\title{
Simultaneous optical observations of long-period gravity waves during AIDA '89
}

\author{
R. H. Wiens, ${ }^{*}$ S. P. Zhang, ${ }^{*}$ R. N. Peterson, ${ }^{*}$ G. G. Shepherd, ${ }^{*}$ C. A. Tepley,$\dagger$ \\ L. KIEFFABER, $\neq$ R. NiCIEJEWSKi $\S$ and J. H. HECHT\| \\ * Inst. for Space and Terrestrial Science, York University, North York, Ontario, Canada M3J 3K1; \\ $\uparrow$ Arecibo Observatory, Arecibo, PR 00613, U.S.A.; † Whitworth College, Spokane, WA 99251 , \\ U.S.A.; §Space Physics Research Laboratory, University of Michigan, Ann Arbor, \\ MI 48109-2143, U.S.A. ; Aerospace Corporation, Los Angeles, CA 90009, U.S.A.
}

(Received in final form 4 February 1992 ; accepted 5 February 1992)

\begin{abstract}
Ground-based optical instrumentation supported the AIDA ' 89 wind measurement comparisons by describing the gravity waves affecting the $80-100 \mathrm{~km}$ altitude region during clear dark hours over Puerto Rico. This study tabulates the characteristics of gravity waves with fractional column emission rate amplitudes up to $30 \%$ and with periods greater than $45 \mathrm{~min}$ as seen in the $\mathrm{O}_{2}$ airglow layer by MORTI, a sensor of $\mathrm{O}_{2}$ rotational temperature and column emission rate in twelve look directions. Data from seven other sensors operating at Guanica and the Arecibo Observatory are then compared with the MORTI data to check the consistency of the entire data set with the wave parameters, primarily velocities, deduced from MORTI. Nine nights of visually distinct crests and troughs were found, one of which was dominated by an evanescent wave and the rest by internal waves. The nights of $5 / 6$ April and 4/5 May 1989 were selected for multi-sensor comparisons. The comparisons showed substantial agreement between the MOR'TI characterizations and the observations by others, and most differences were attributed to complexities introduced by higher frequency components with shorter coherence distances. Nightly summaries of the $\mathrm{O}_{2}$ rotational temperature and column emission rate are also given.
\end{abstract}

\section{INTRODUCTION}

As part of the AIDA ' 89 campaign to compare wind measurements by all available techniques, it was early recognized that the state of the atmosphere in which these wind measurements were made had to be described in some quantitative way. In particular, the influence of gravity wave activity on the wind measurements had to be assessed, and this assessment was to be based at least partially on optical instruments measuring the column emission rates and rotational temperatures of airglow layers in the 80 $100 \mathrm{~km}$ altitude range. The current state of understanding of the interaction of gravity waves with the airglow is well summarized by VIERECK (1991), who concluded that using the airglow to study gravity waves requires complex analysis, and that more effort in the observational area is necessary. The present paper, in an effort to contribute to both these needs, seeks to establish those cases in which column emission rates of airglow emissions exhibited oscillatory behavior with discernible periods of $45 \mathrm{~min}$ or more from one of the many ground-based instruments operating in Puerto Rico at that time. The mesopause oxygen rotational temperature imager, MORTI, was selected for this task because it provided enough spatial information to enable the quantitative characterization of these oscillations in terms of the kinematic gravity wave parameters, period and horizontal velocity, from which the remaining parameters, horizontal and vertical wavelength and vertical speed, could be found. When this characterization was complete, two cases were chosen for comparison with simultaneously recorded data from the other optical instruments. The consistency of the oscillatory behavior of data from these other instruments with the MORTI characterization parameters is then interpreted as confirmation of the parameterization, and this confirmation for two cases is extrapolated to all the MORTI data set consisting of nine 'quasi-monochromatic' wave sequences. The list of these parameters (Table 3 ) is then submitted as the tentative summary of the optical observers' findings for further analysis of the wind comparisons. This report is therefore preliminary. A later study should include the Fouricr decomposition of all the data from all the stations and make use of the spatial information given by their locations and pointing directions to determine the periods and horizontal velocities from the broadest data set possible. The radio measurements of the wind 


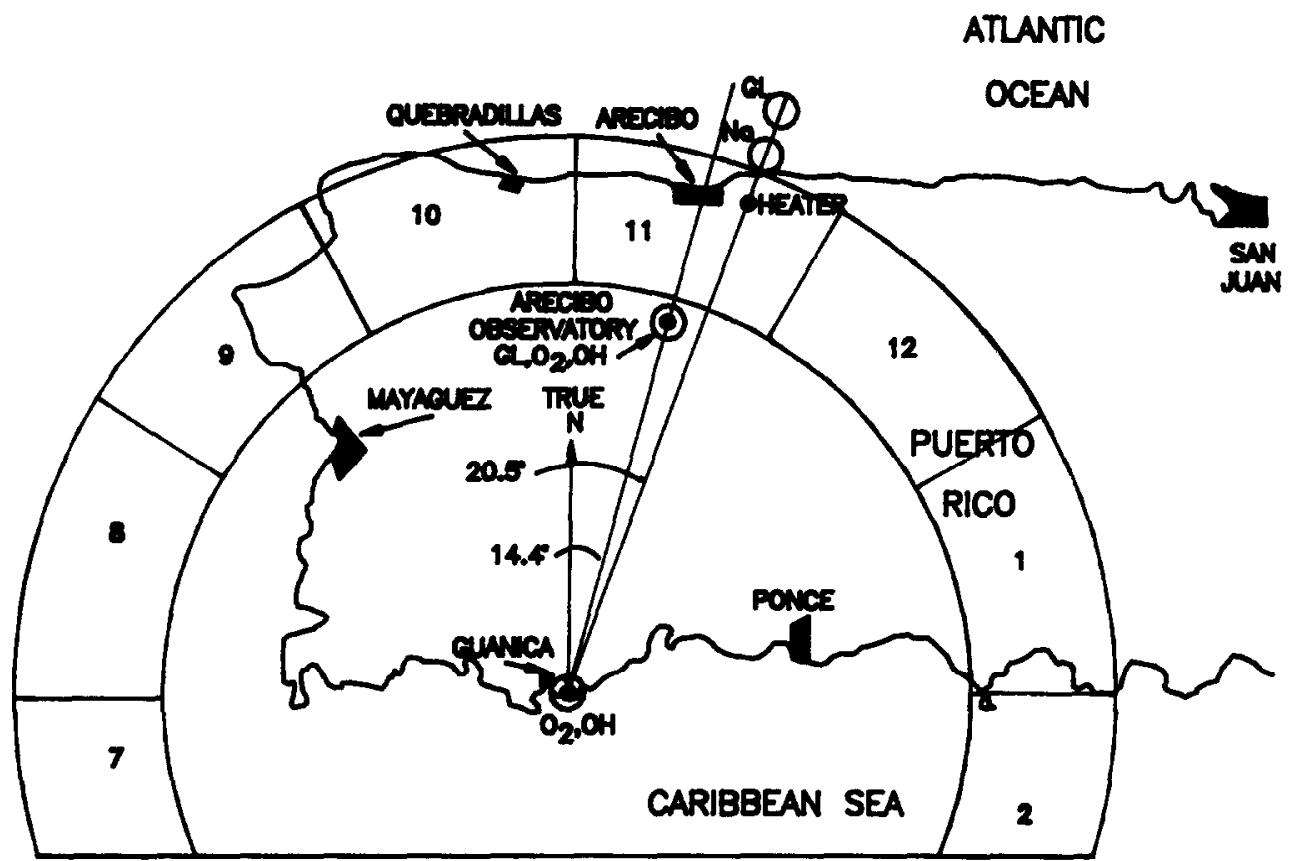

Fig. 1. Map of Puerto Rico showing locations of stations and target areas observed by optical sensors listed in Table 1 during AIDA ' 89.

velocities summarized in accompanying papers should then be incorporated into the Doppler shift corrections, while only preliminary optical wind measurements were considered for this purpose here.

\section{EXPERIMENTAL CONFIGURATION}

Ground-based optical instruments participating in the AIDA '89 campaign were located at the Arecibo Observatory in the northern interior of Puerto Rico and at Guanica on the south coast as shown in the map (Fig. 1). The sensors used at the two stations are listed in Table 1, identified by the institution responsible, the airglow species targeted, a nominal altitude of the maximum emission rate of the airglow layer, and the location of the field of view projected out to the airglow layer. All were assumed to be pointed at the zenith except for those of Whitworth, aimed at $55^{\circ}$ elevation over the Heater and shown in Fig. 1 as small circular fields labelled GL and $\mathrm{Na}$, and MORTI which views an annular field that is analyzed in segments as outlined and enumerated on the map of Fig. 1. The $\mathrm{O}_{2}$ sensors all measure the $\mathrm{O}_{2}$ Atmospheric $\left(b^{\prime} \Sigma_{q}^{+}-X^{3} \Sigma_{g}^{-}\right)(0-1)$ band around $864.5 \mathrm{~nm}$. The code GL refers to the green line or OI( $\left.{ }^{\prime} \mathrm{S}-{ }^{3} \mathrm{P}\right)$ transition at $557.7 \mathrm{~nm}$, and $\mathrm{Na}$ refers to the nightglow sodium D doublet at $589.3 \mathrm{~nm}$. The Aerospace OH sensor measured the Meinel (8-3) band at visible wavelengths, whereas the Michigan sensor measured the (4-2) band in the short-wave infrared region of

Table I. AIDA '89 optical sensors

\begin{tabular}{llccl}
\hline Station & Institution & Airglow & Altitude $(\mathrm{km})$ & Target area \\
\hline Observatory & Arecibo & $\mathrm{O}_{2}$ & 94 & Observatory \\
Observatory & Arecibo & $\mathrm{GL}$ & 97 & Observatory \\
Observatory & Aerospace & $\mathrm{O}_{2}$ & 94 & Observatory \\
Observatory & Aerospace & $\mathrm{OH}$ & 85 & Observatory \\
Guanica & Michigan & $\mathrm{OH}$ & 85 & Guanica \\
Guanica & York (MORTI) & $\mathrm{O}_{2}$ & 94 & Guanica \\
Granica & Whitworth & $\mathrm{GL}$ & 97 & Heater \\
Guanica & Whitworth & $\mathrm{Na}$ & $9 \mathrm{I}$ & Heater \\
\hline
\end{tabular}


the spectrum. All of the institutions listed in Table 1 gathered data of other kinds as well, usually rotational temperatures, but, as shown by TARASICK and SHEPHERD (1992), temperature fluctuations can be expected to have fractional amplitudes that are only one third or less those of the column emission rate fluctuations. TARASICK and SHEPHERD (1992) also find a deterministic relationship between temperature and column emission rate fluctuations, which implies that including the temperalures would not add an independent parameter, but would decrease the amplitude to noise ratio. MORTI temperature data are however, shown for comparison in the two examples in keeping with the MORTI basis of this analysis. A complete study of the MORTI temperature fluctuations and their relation to the column emission rate fluctuations is given by $\mathrm{ZHANG}$ et al. (1993).

Although some efforts at intercalibration between the various sensors of the same airglow species were made as described in accompanying papers, absolute calibrations are not required by the present study. Fluctuations are more conveniently described as fractional (percentage) deviations from the mean of the night's average value of the measured quantity from that sensor. The nights themselves are of different lengths for different stations largely because of differences in weather At Guanica, for instance, most evenings in April were overcast, clearing only shortly before midnight, but after midnight the sky was generally quite clear. The AIDA campaign was scheduled to exclude periods of bright moonlight, and the subtraction of weak moon or stray ground light was handled by the operator of each sensor.

The analysis of the MORTI data is described by WIENS et al. (1991) and in more detail by ZHANG et al. (1993). Comparison data from other sensors were manually digitized from operators' processed output in graphical form at time intervals chosen to give a fair representation of the variability evident in the data. The extracted values were then plotted on paper of standard format as in Fig. 3 and connected by straight lines without curve fitting or smoothing. The discrete points indicated in the graphs of the remaining figures thus show the sampling period of the digitization, which may or may not have been limited by the time required for the actual measurements. Phase differences between patterns were measured by superposing one of these graphs over another and sliding it horizontally until a visually acceptable fit was found. Comparisons are thus subject to errors in the pointing of the sensor, timing the measurements, and scaling the data, and these crror sources have not yet been properly quantified.

\section{DATA SUMMARY}

Some understanding of the general state of the airglow during the AIDA ' 89 period may be gained by reference to Table 2, where the column emission rates and rotational temperatures of the $\mathrm{O}_{2}$ layer, averaged over the period 2300-0430 AST and over the full annular field of MORTI, are listed for cach night of MORTI operation. As discussed by WiENs et al. (1991), the accuracies of the column emission rates for MORTI are $\pm 10 \%$ and those of temperature are $\pm 5 \mathrm{~K}$; the precisions are, respectively, $\pm 2 \%$ and $\pm 2 \mathrm{~K}$ for individual measurements, but $\pm 1 \%$ and $\pm 1 \mathrm{~K}$ in Table 2 because of the large number of measurements in the averages. The brightest night, $3 / 4$ May, was also the warmest night at the $\mathrm{O}_{2}$ airglow altitude. The coldest night, 6/7 April, was also the faintest. A similar relationship between column emission rate and rotational temperature of the $\mathrm{O}_{2}$ airglow was reported by TAKAHASHI et al. (1990) at $23 \mathrm{~S}$. The MORTI column emission rates have been compared with the green line emission rates and the planetary geomagnetic indices for the AIDA ' 89 period by BIRD et al. (1993).

The harmonic analysis (ZHANG et al., 1993) of the nightly sequence of MORTI column emission rates for each of the twelve segments of the annular field of view, shown in Fig. 2, provided apparent periods and horizontal velocities for large amplitude waves, given in Table 3 with their estimated accuracies. Only nine nights of suitably identifiable wave activity were found in the 22 nights available for analysis. The apparent periods of the waves listed are all greater than 45 min because that defined the scope of this paper. The lengths of longer period waves were limited by the data sequence having to be long enough to allow for such a wave to be clearly identifiable. One especially interesting night was 4/5 May, when an evanescent wave was observed. The suggestion that these would account for many optical wave observations was made by TARASICK and HINES (1990) from an examination of the high-altitude data of VIERECK and DEeHr (1989). Our finding one night of evanescence out of nine nights in which long period waves were observed suggests that they are at least common if not frequent at low latitudes. 4/5 May was also the night of highest planetary $K$ index during the MORTI AIDA observation period. The remaining eight cases all gave waves of two identifiable periods, each with its own velocity. Differences in velocity direction could be the result of higher frequency components in the data sequences perturbing the two velocity determinations differently, but whether the two components are really two different waves or whether they are the same 
Table 2. Average temperature and emission rate of $\mathrm{O}_{2}$ airglow from MORTI over the period $2300-0430$ AST

\begin{tabular}{lccc}
\hline \multicolumn{1}{c}{ Date } & Number of images & $\begin{array}{c}\text { Temperature } \\
\bar{T}(K)\end{array}$ & $\begin{array}{c}\text { Emission rate } \\
\bar{E}(R)\end{array}$ \\
\hline 3/4 April & 76 & 198 & 501 \\
4/5 April & 46 & 186 & 315 \\
5/6 April & 51 & 200 & 608 \\
6/7 April & 92 & 172 & 271 \\
7/8 April & 59 & 179 & 318 \\
8/9 April & 83 & 192 & 381 \\
9/10 April & 50 & 195 & 474 \\
10/11 April & 78 & 193 & 314 \\
11/12 April & 65 & 201 & 587 \\
12/13 April & 79 & 186 & 388 \\
13/14 April & 58 & 201 & 541 \\
30 April/1 May & 63 & 189 & 473 \\
1/2 May & 70 & 197 & 424 \\
2/3 May & 45 & 193 & 417 \\
3/4 May & 76 & 220 & 917 \\
4/5 May & 57 & 209 & 915 \\
5/6 May & 58 & 192 & 626 \\
6/7 May & 53 & 195 & 585 \\
7/8 May & 53 & 196 & 547 \\
8/9 May & 72 & 184 & 447 \\
9/10 May & 19 & 181 & 326 \\
10/11 May & 56 & 204 & 499 \\
\hline
\end{tabular}

wave perturbed by higher frequencies, the result is that the waves are always complex even though they will be referred to as 'quasi-monochromatic' for convenience.

It must be emphasized that Table 3 lists only the directly measured gravity wave parameters with no attempt to correct for Doppler effects. The extensive body of radio measurements of winds during the campaign was not available for this preliminary study, but optical measurements of green line (GL) winds from Arecibo and Guanica are now available from BIRD et al. (1993). At present the MORTI analysis only allows for a background wind that is constant in time, whereas the measured winds are quite variable. An average of the wind components in the direction of the apparent wave velocity was extracted from the GL wind data and used to calculate the intrinsic periods and vertical wavelengths listed in Table 4 . Vertical wavelengths were computed from the dispersion relation using the intrinsic period and a speed of sound of $276 \mathrm{~m} / \mathrm{s}$. The vertical wavelengths found in this way are all at least twice as long as the thickness of the $\mathrm{O}_{2}$ airglow layer, as they must be to avoid significant cancellation when observed from the ground. In the tabulated cases the wind components are less than $20 \%$ of the wave speed and have little effect on the comparisons to be made.

\section{COMPARISON CASE I: AN INTERNAL GRAVITY WAVE}

As shown in Table 3 nine cases of long-period wave activity are reported, and eight of these were primarily internal gravity waves. The internal gravity wave case of $5 / 6$ April was observed by more optical instruments than any other and therefore is used here for a comparison study of MORTI with the other sensors. The MORTI column emission rate is plotted for each of the twelve segments in Fig. 2, where segment numbers correspond to positions indicated on the map (Fig. 1). Differences in the shapes of the traces as well as the phases are evident, showing that we are not dealing with a simple, plane, monochromatic wave, but enough similarity exists to suggest that some main features are common to all segments. The dominant features were extracted from the traces following the method of Press and Teukolsky (1988) and found to have periods of 126 and $46 \mathrm{~min}$, the longer period wave having an amplitude 3.5 times that of the shorter. The longer wave has a horizontal velocity of $102 \mathrm{~m} / \mathrm{s}$ toward the direction ENE and the shorter a velocity of $83 \mathrm{~m} / \mathrm{s}$ toward the NNE. On the assumption of zero background wind velocity, these periods lead to vertical velocity components of 4.2 and $9.0 \mathrm{~m} / \mathrm{s}$, respectively.

A comparison of four $\mathrm{O}_{2}$ column emission rate 


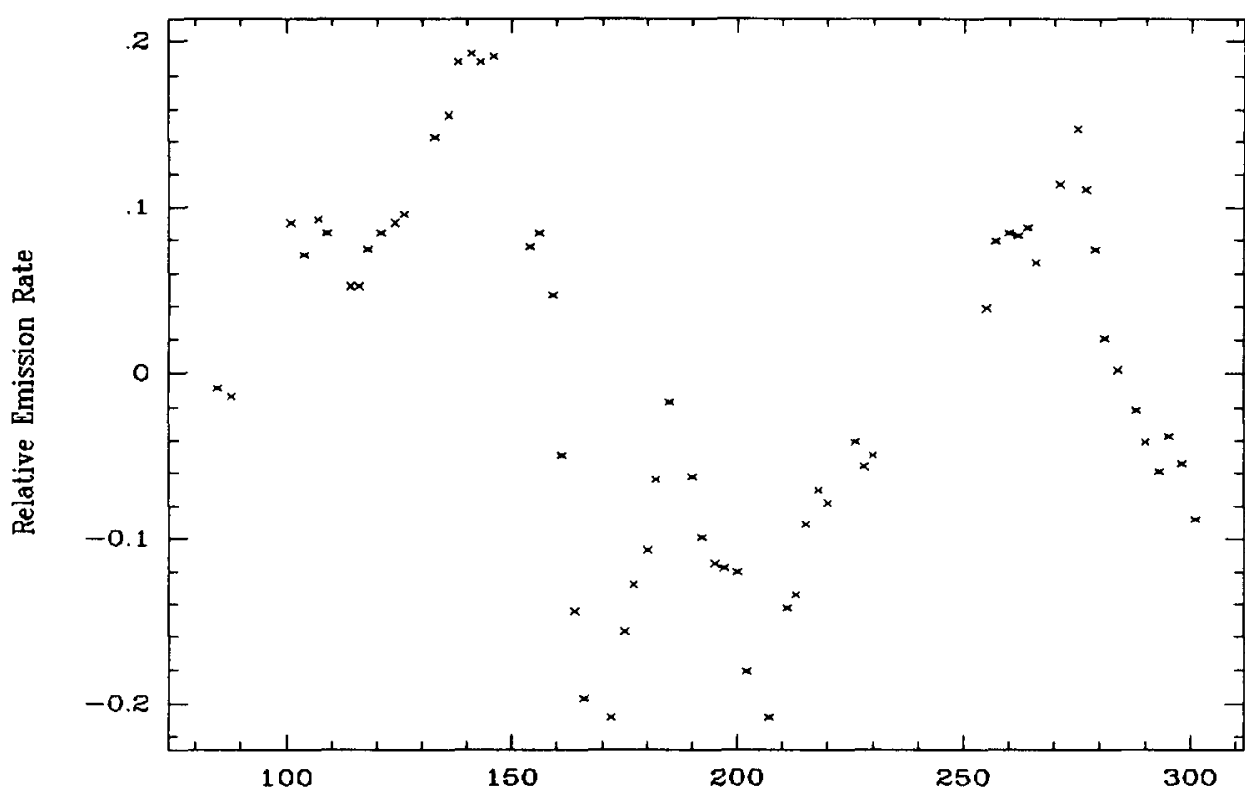

Local Time (minutes) from midnight, Sector 1

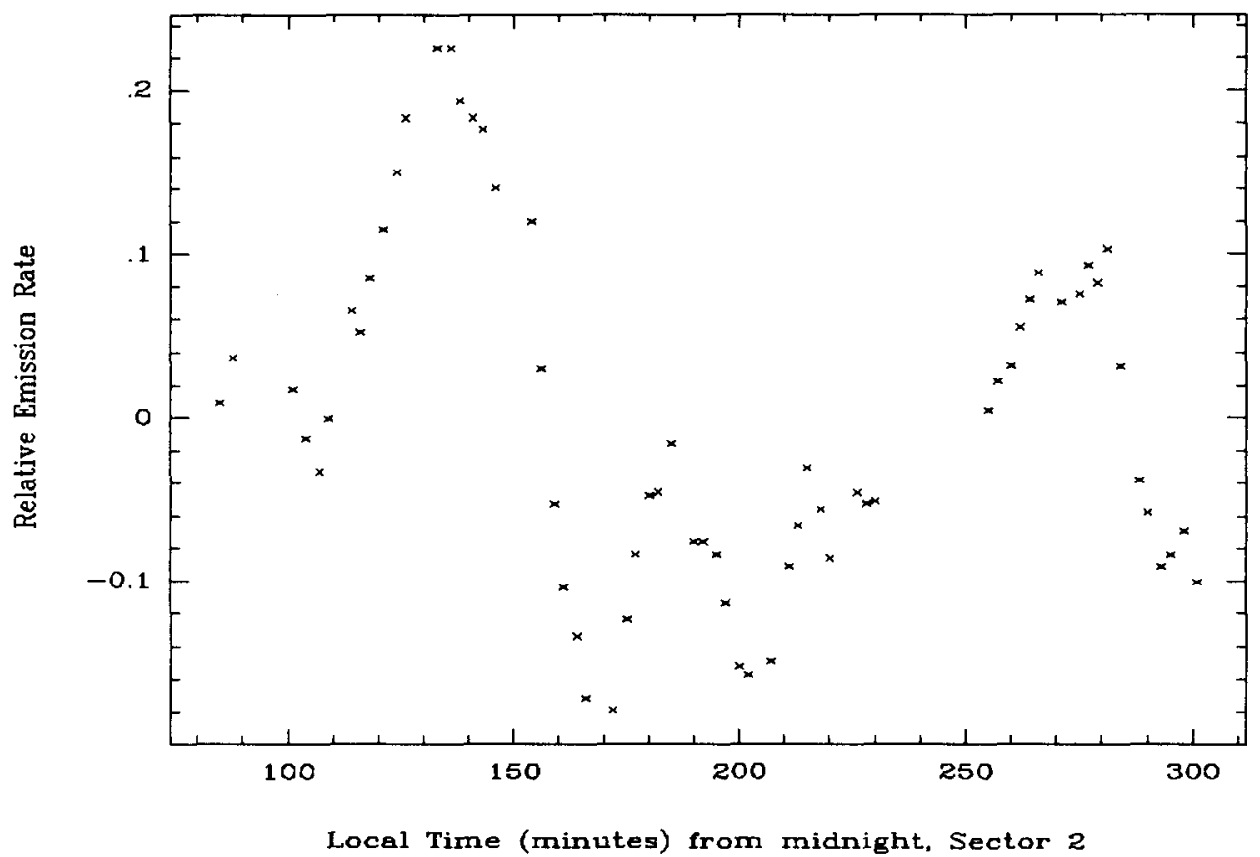

Fig. 2. 


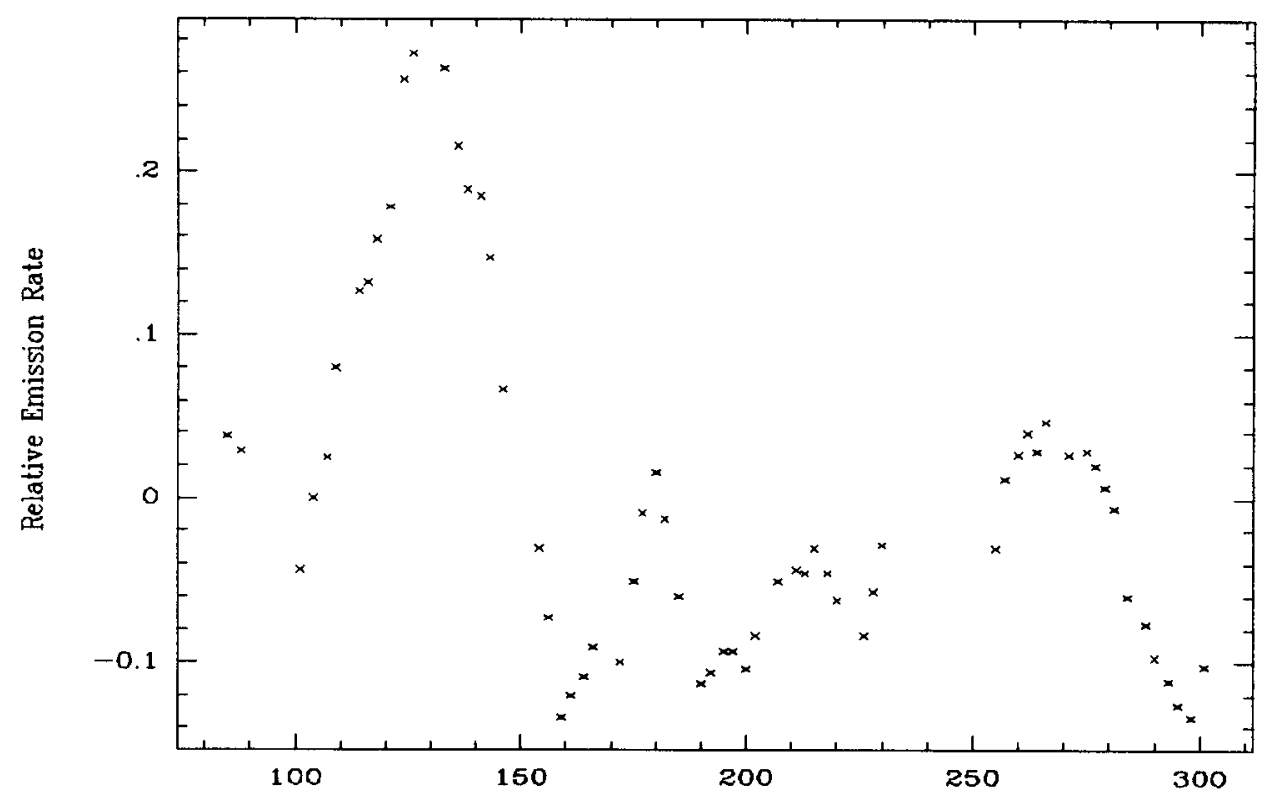

Local Time (minutes) from midnight, Sector 3

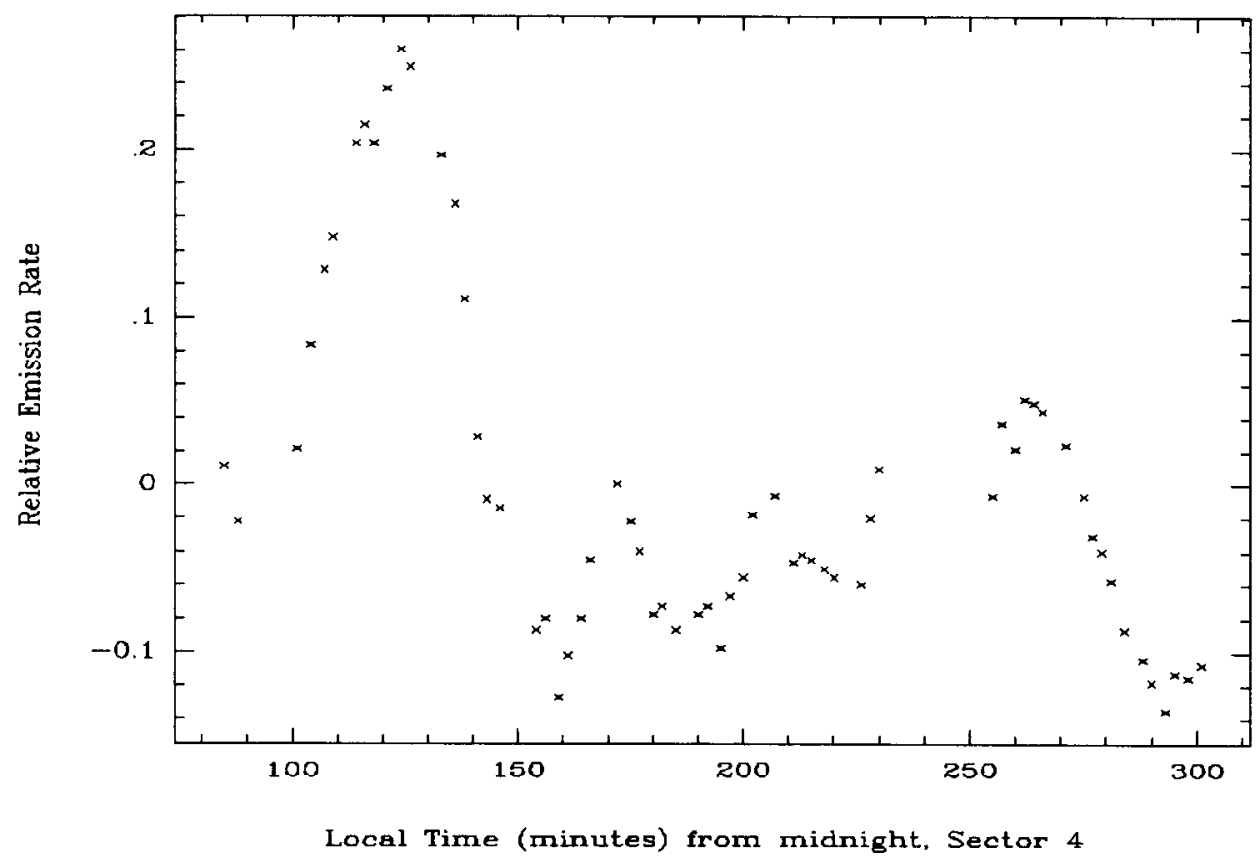

Fig. 2 (continued). 

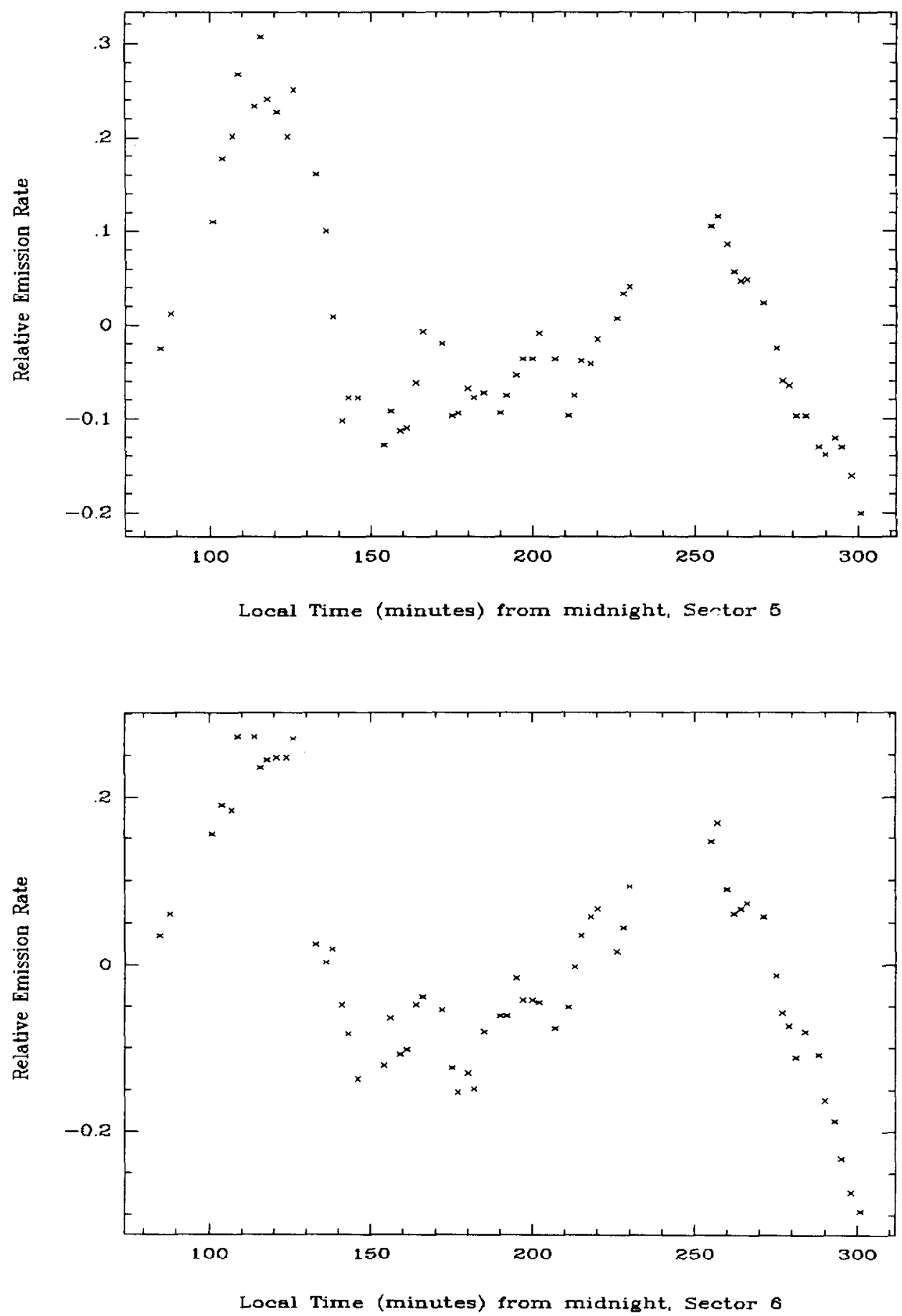

Fig. 2 (continued). 




Local Time (minutes) from midnight, Sector 7

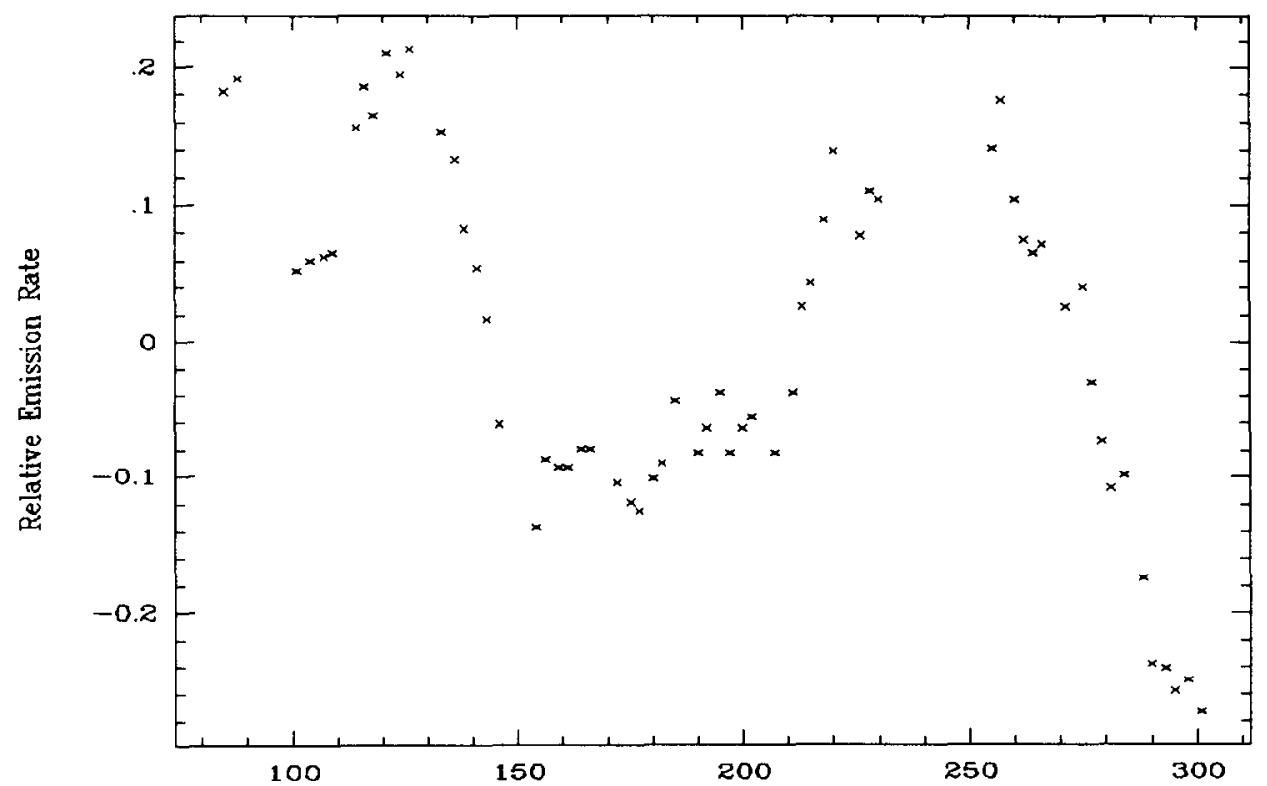

Local Time (minutes) from midnight, Sector 8

Fig. 2 (continued). 


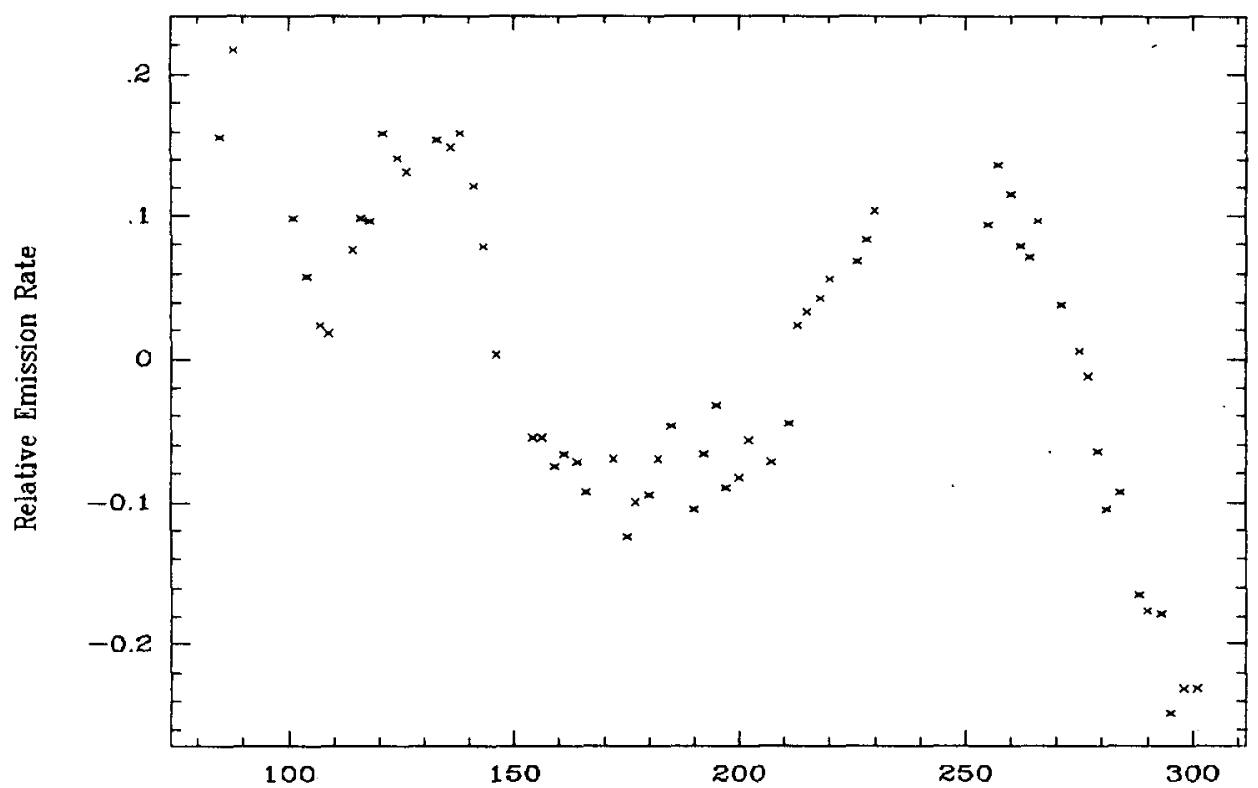

Local Time (minutes) from midnight, Sector 8

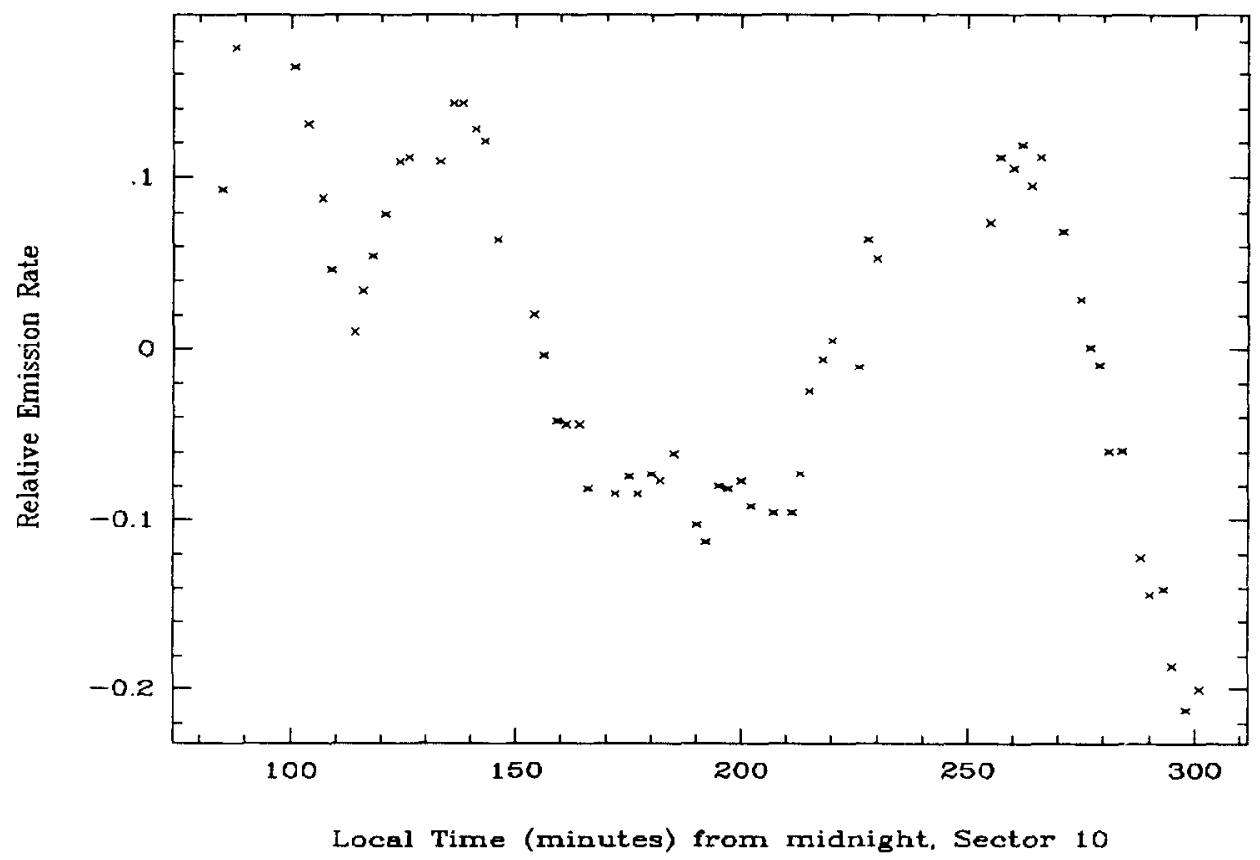

Fig. 2 (continued). 

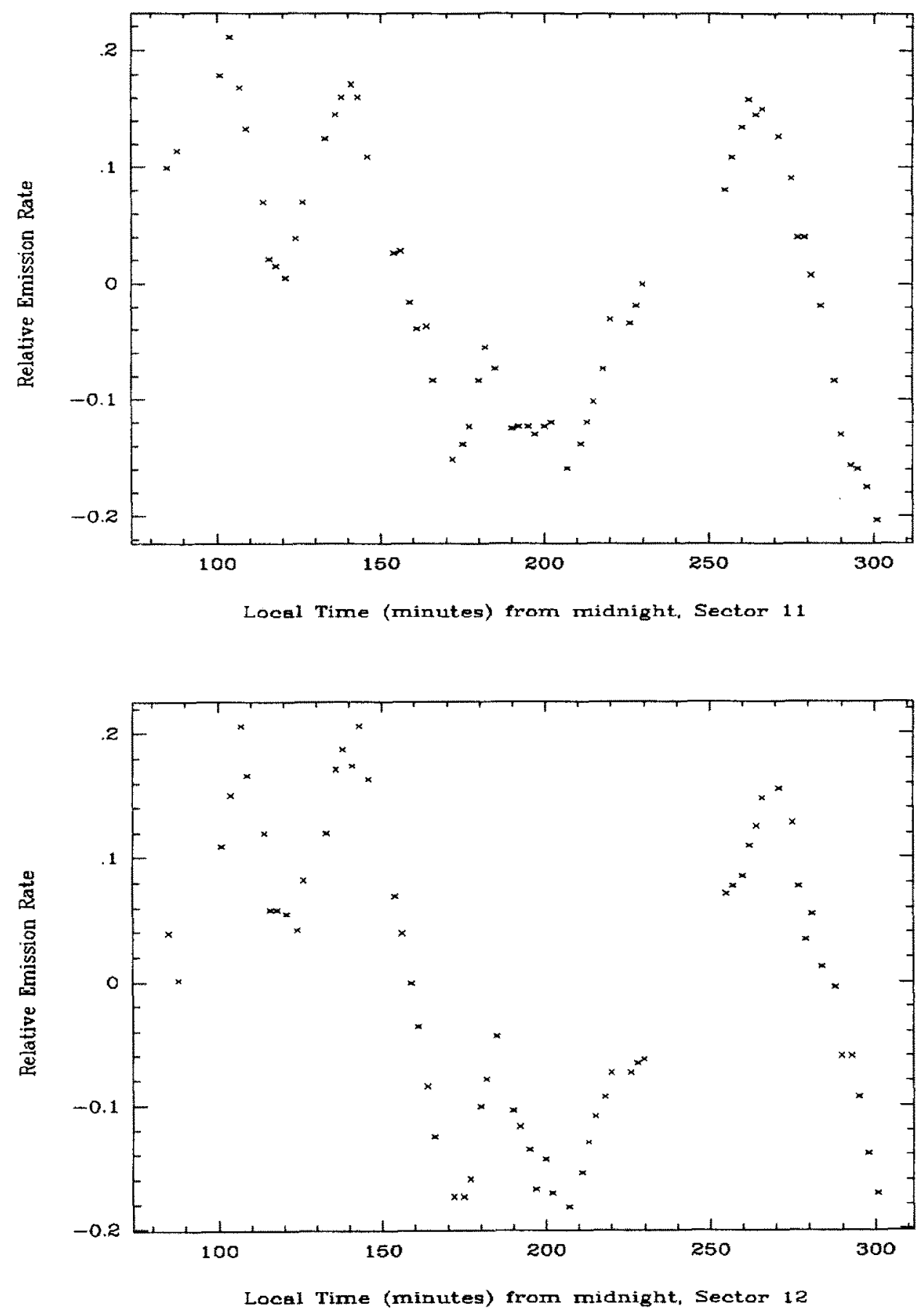

Fig. 2. Column emission rate sequences for each of the twelve segments of the annular field of view of MORTI for $5 / 6$ April 1989, from which characterizations as in Table 3 were deduced. Corresponding segment numbers are located on the map (Fig. 1). 
Table 3. Characteristics of gravity waves observed by MORTI during the AIDA ' 89 campaign

\begin{tabular}{cccccc}
\hline \multicolumn{1}{c}{ Date } & $\begin{array}{c}\text { Period } \\
(\mathrm{min})\end{array}$ & $\begin{array}{c}\text { Speed of phase } \\
(\mathrm{m} / \mathrm{s})\end{array}$ & $\begin{array}{c}\lambda_{x} \\
(\mathrm{~km})\end{array}$ & $\begin{array}{c}\text { Azimuth* of } \\
\text { horizontal velocity }\end{array}$ & $A_{B} \dagger$ \\
\hline 5/6 April & $126 \pm 5$ & $102 \pm 5$ & $774 \pm 70$ & $57^{\circ} \pm 10^{\circ}$ & $0.14 \pm 0.02$ \\
& $46 \pm 5$ & $83 \pm 5$ & $228 \pm 34$ & $29 \pm 10^{\circ}$ & $0.04 \pm 0.01$ \\
8/9 April & $308 \pm 5$ & $146 \pm 5$ & $2705 \pm 136$ & $254^{\circ} \pm 10$ & $0.20 \pm 0.02$ \\
11/12 April & $160 \pm 5$ & $276 \pm 10$ & $2654 \pm 164$ & $324 \pm 15^{\circ}$ & $0.11 \pm 0.01$ \\
30 April/1 May & $150 \pm 5$ & $166 \pm 5$ & $1497 \pm 75$ & $71 \pm 10^{\circ}$ & $0.19 \pm 0.02$ \\
& $340 \pm 5$ & $48 \pm 5$ & $989 \pm 110$ & $180 \pm 10^{\circ}$ & $0.11 \pm 0.01$ \\
3/4 May & $278 \pm 5$ & $174 \pm 10$ & $2896 \pm 220$ & $14 \pm 15^{\circ}$ & $0.23 \pm 0.02$ \\
4/5 May & $106 \pm 5$ & $282 \pm 5$ & $1795 \pm 116$ & $302 \pm 10^{\circ}$ & $0.09 \pm 0.01$ \\
& $48 \pm 5$ & $71 \pm 5$ & $203 \pm 36$ & $347 \pm 10^{\prime}$ & $0.02 \pm 0.01$ \\
5/6 May & $162 \pm 5$ & $92 \pm 5$ & $890 \pm 76$ & $1 \pm 10^{\circ}$ & $0.30 \pm 0.03$ \\
& $82 \pm 5$ & $93 \pm 5$ & $456 \pm 45$ & $72 \pm 10^{\circ}$ & $0.13 \pm 0.02$ \\
6/7 May & $132 \pm 5$ & $64 \pm 5$ & $505 \pm 60$ & $81 \pm 10$ & $0.13 \pm 0.02$ \\
& $80 \pm 5$ & $217 \pm 5$ & $1040 \pm 80$ & $29^{\circ} \pm 10^{\circ}$ & $0.07 \pm 0.01$ \\
8/9 May & $138 \pm 5$ & $157 \pm 10$ & $1296 \pm 130$ & $218 \pm 10^{\circ}$ & $0.09 \pm 0.01$ \\
\hline
\end{tabular}

* Measured from north positive to east; $\dagger$ the wave amplitude in the emission rate.

Table 4. Doppler shifted vertical wavelength

\begin{tabular}{lcrcccc}
\hline Date & $\begin{array}{c}\text { Observed period } \\
(\mathrm{min})\end{array}$ & $\begin{array}{c}\hat{\lambda}_{\mathrm{r}} \\
(\mathrm{km})\end{array}$ & $\begin{array}{c}\hat{\lambda}^{*} \\
(\mathrm{~km})\end{array}$ & $\begin{array}{c}\bar{u}^{\dagger} \\
(\mathrm{m} / \mathrm{s})\end{array}$ & $\begin{array}{c}\text { Intrinsic period } \\
(\mathrm{min})\end{array}$ & $\begin{array}{c}\hat{\lambda}_{z} \\
(\mathrm{~km})\end{array}$ \\
\hline 5/6 April & 126 & 774 & $32 \pm 3$ & +15 & $148 \pm 5$ & $27 \pm 2$ \\
& 46 & 228 & $25 \pm 3$ & +20 & $56 \pm 5$ & $19 \pm 1$ \\
8/9 April & 308 & 2705 & $53 \pm 2$ & -34 & $250 \pm 5$ & $75 \pm 10$ \\
11/12 April & 160 & 2654 & $\infty$ & -6 & $x$ & $184 \pm 15$ \\
3/4 May & 278 & 2896 & $70 \pm 5$ & +14 & $302 \pm 5$ & $66 \pm 5$ \\
6/7 May & 132 & 505 & $19 \pm 2$ & -20 & $101 \pm 5$ & $26 \pm 4$ \\
& 80 & 1040 & $126 \pm 7$ & -15 & $74 \pm 5$ & $181 \pm 15$ \\
\hline
\end{tabular}

* Assuming the mean flow to be at rest: + component of wind velocity along wave direction (BiRp et (al. 1993).

sequences for $5 / 6$ April is shown in Fig. 3. The fullring average for MORTI is centered on Guanica, and it is interesting first of all to note the differences between this and the northernmost MORTI segment. segment 11. Several features that do match in this pair appear about 6 min earlier in the full-ring average than in the northern segment, consistent with northward movement. Also, the shorter period component is pronounced in the northern segment, but less evident in the full-ring average, indicating that the shorter wave increases in amplitude toward the north. This feature is quite noticeable in Fig. 2. The Aerospace and Arecibo sensors, both located at the observatory and hence intermediate between MORTI full and MORTI north, show an intermediate degree of splitting of the first main crest into two, again arguing for an amplitude increase of the shorter period component toward the north. The phase difference between MORTI north and Arecibo is a result of the proximity of the two fields of view. It is worth noting that the relative amplitudes of the patterns are similar for the four $\mathrm{O}_{2}$ cases.
The two green line photometer traces, Arecibo and Whitworth, are plotted in Fig. 4, where Whitworth may appear to lead. A wave moving as suggested should be observed slightly sooner by Arecibo according to Fig. 1, but since Whitworth has a small $\left(1^{\circ}\right)$ field of view and is pointed at a fairly large zenith angle, we attribute this discrepancy to a combination of pointing and scaling errors. A more interesting comparison is between the green line and the $\mathrm{O}_{2}$ traces of Arecibo, also in Fig. 4. For these two sensors, both pointed at the zenith from the same place, the green line trace, $\mathrm{GL}$, leads the $\mathrm{O}_{2}$ trace by 6 min, considering the envelope of the first large crest, although not the finer features. If we assume a difference in altitude between the two layers of $2 \mathrm{~km}$, the wave is propagating downward at a speed of $5.5 \mathrm{~m} / \mathrm{s}$, which is consistent with the MORTI vertical velocity for the long wave but which adds the important information of vertical sense. As pointed out by HINEs (1960), such downward propagation implies an upward energy flux and tells us that the origin of the wave is in the lower atmosphere. A similar argument holds in the com- 


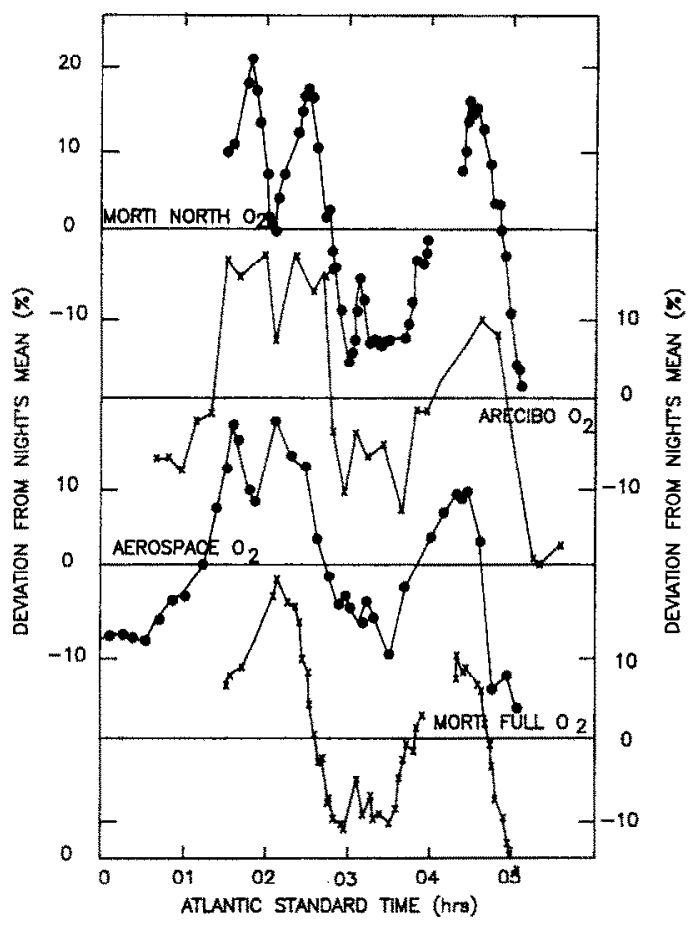

Fig. 3. Comparison plots of four $\mathrm{O}_{2}$ column emission rate sequences for 5/6 April 1989, over Puerto Rico.

parison between the Whitworth GL (Fig. 4) and the Whitworth Na (Fig. 6), where GL can be shown to lead $\mathrm{Na}$ by $12 \mathrm{~min}$. In this case we deduce a vertical wave component of $8.3 \mathrm{~m} / \mathrm{s}$ downward. With the difficulties of choosing features to match amid the fine structure, these efforts to establish the vertical sense of propagation can hardly be regarded as definitive, but the fact that possibilities for consistent matching appear giving vertical speeds within a factor of two of those expected from the MORTI data lends some credibility to the downward choice.

The downward phase propagation should be more dramatically evident in a comparison between the $\mathrm{O}_{2}$ and the $\mathrm{OH}$ patterns from a single station. If the vertical speed is $4 \mathrm{~m} / \mathrm{s}$ as calculated from the MORTI analysis and the $\mathrm{OH}$ layer is $10 \mathrm{~km}$ below the $\mathrm{O}_{2}$, the $\mathrm{O}_{2}$ trace may be expected to lead the corresponding $\mathrm{OH}$ trace by $42 \mathrm{~min}$. However, although the greater separation makes the phase shift larger, it also allows for different effects to influence the two layers. The data from the two Aerospace sensors are compared in Fig. 5a, and those from Guanica, that is, the Michigan $\mathrm{OH}$ and the MORTI full-ring traces, are compared in Fig. 5b. In neither case is the similarity

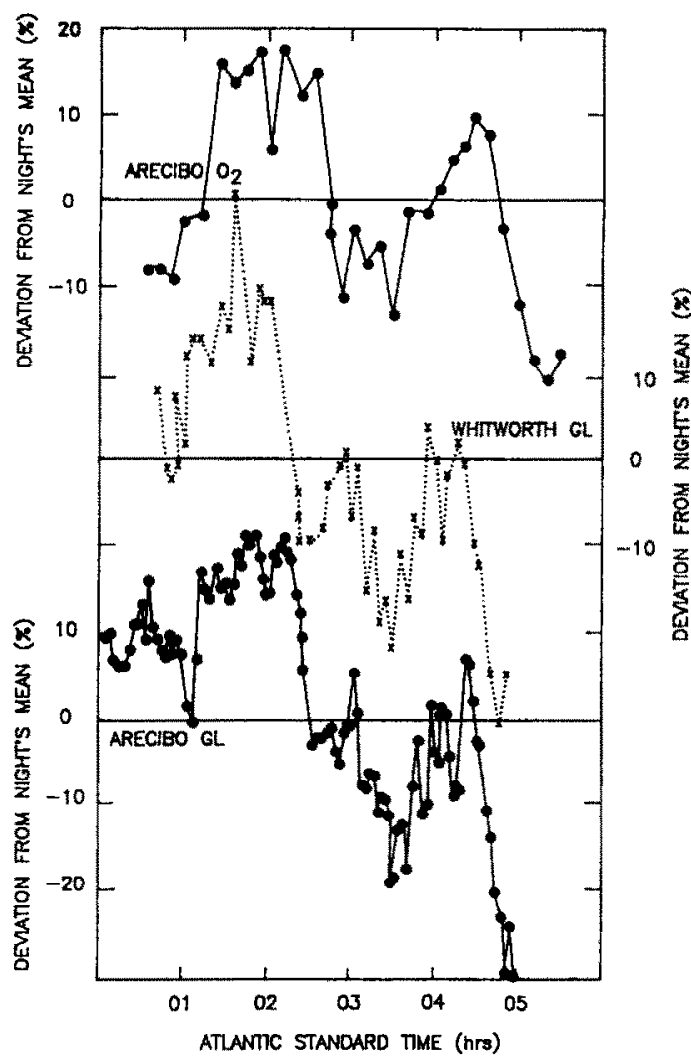

Fig. 4. Comparison plots of green line and $\mathrm{O}_{2}$ column emission rate sequences for 5/6 April 1989, over Puerto Rico.

between $\mathrm{O}_{2}$ and $\mathrm{OH}$ sufficient to discern a single phase shift. In the Aerospace case, Fig. 5a, the $\mathrm{O}_{2}$ could be said to lead the $\mathrm{OH}$ by 27 or $63 \mathrm{~min}$, but to force that lead to 42 min causes the second $\mathrm{OH}$ peak at 0342 to line up with an $\mathrm{O}_{2}$ trough. The comparison between the two Guanica patterns, Fig. 5b, also gives ambiguous fits. Forcing a $42 \mathrm{~min}$ lead by the $\mathrm{O}_{2}$ matches peaks but without any regard for their magnitudes. A 42-min lead by the $\mathrm{OH}$, on the other hand, gives a slightly better match, which in itself might imply upward propagation. However, a similar $\mathrm{OH}$ lead in the Aerospace data does not match the $\mathrm{OH}$ and $\mathrm{GL}$ patterns at the observatory. The difficulty may be better understood by noting that the $\mathrm{OH}$ pattern observed at the observatory by Aerospace and that observed at Guanica by Michigan are not wellmatched with any phase difference. The distance between the two observation points seems to be greater than the coherence length of the complex wave activity at this altitude, at least in this case. An alternate explanation of the lack of correlation between the 


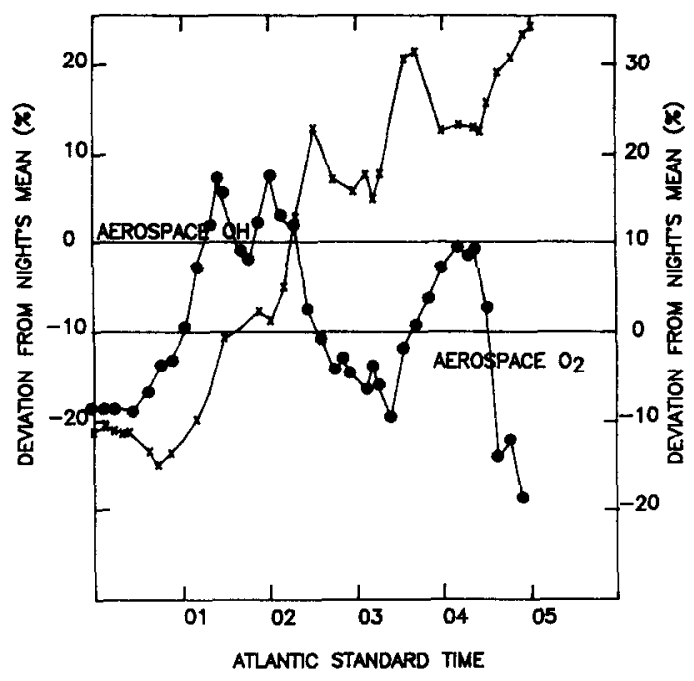

Fig. 5a. Comparison of Aerospace $\mathrm{OH}$ and $\mathrm{O}_{2}$ column emission rate sequences for 5/6 April 1989, over Puerto Rico.

$\mathrm{O}_{2}$ and the $\mathrm{OH}$ behavior is given in the accompanying paper by HECHT et al. (1993).

An easier way of determining the vertical sense of the wave from MORTI data alone was suggested by TARASICK and HINES (1990). The temperature fluctuations should lead the column emission rate fluctuations for upward energy propagation or downward phase. The full-ring rotational temperature trace for $5 / 6$ April is shown in Fig. 5b, but the apparent zero phase difference in this case renders that criterion inapplicable.

The Whitworth Na sensor provides several interesting comparisons shown in Fig. 6. Reasonable similarity between the $\mathrm{Na}$ and the Michigan $\mathrm{OH}$ traces appears, the $\mathrm{OH}$ leading the $\mathrm{Na}$ by $20 \mathrm{~min}$. This suggests a wave moving in the direction NNE at a speed of $51 \mathrm{~m} / \mathrm{s}$, the Guanica-Heater distance in Fig. 1 being $61 \mathrm{~km}$. To the extent that the MORTI derived speeds are applicable at these lower altitudes and that the $\mathrm{Na}$ and $\mathrm{OH}$ are at the same height, the trace speed along the Guanica-Heater line would be $69 \mathrm{~m} / \mathrm{s}$ for the long wave and $55 \mathrm{~m} / \mathrm{s}$ for the shorter one. While these do not constitute full agreement, the usual as yet unquantified inaccuracies of pointing, timing, and scaling, can be invoked to explain the discrepancies.

The upward trend in the $\mathrm{Na}$ and $\mathrm{OH}$ traces of Fig. 6 is also evident in the Aerospace $\mathrm{OH}$ trace in Fig. 5a, but the opposite tendency is apparent in the Whitworth and Arecibo GL traces of Fig. 4, and to a lesser extent, the $\mathrm{O}_{2}$ traces of Fig. 3. An internal wave is suggested, but because the data set is not long enough

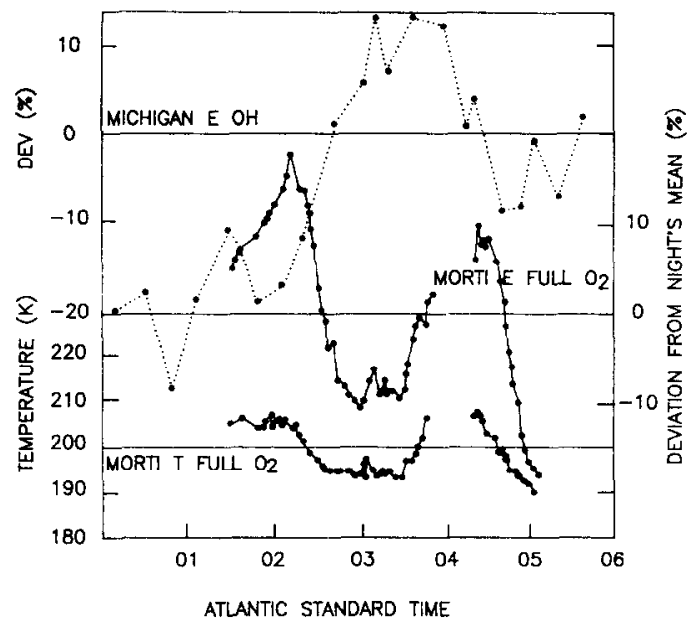

Fig. 5b. Comparison plots of $\mathrm{OH}$ and $\mathrm{O}_{2}$ column emission rate $(E)$ and $\mathrm{O}_{2}$ rotational temperature $(T)$ sequences for 5/6 April 1989, over Guanica, Puerto Rico.

to characterize it, one may only speculate on some of its properties. If the trend represents a maximum of half the wave period, then the period must be at least twice $5 \mathrm{~h}$ or $600 \mathrm{~min}$. If $\mathrm{GL}$ and $\mathrm{OH}$ are $10 \mathrm{~km}$ apart and fully out of phase, the vertical wavelength must be at least $20 \mathrm{~km}$. By the proportionality

$$
\tau_{\tau_{y}}=\frac{\hat{\lambda}_{x}}{\lambda_{z}}
$$

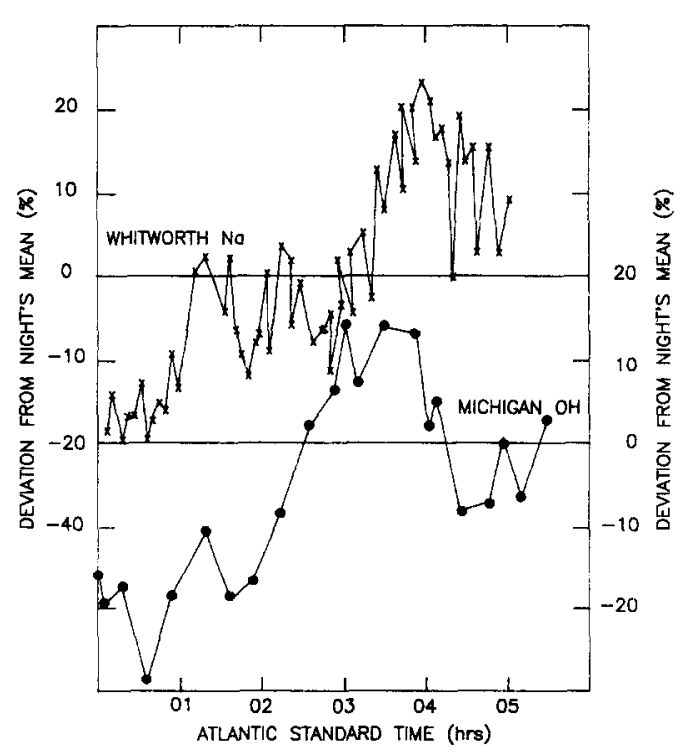

Fig. 6. Comparison plots of $\mathrm{OH}$ and $\mathrm{Na}$ column emission rate sequences for 5/6 April 1989 , over Puerto Rico. 
with $\tau_{y}$ the Brunt-Väisälä period of 5 min, the horizontal wavelength, $\lambda_{x}$, is $2400 \mathrm{~km}$ at least. Such a wave is not unreasonable according to the viscosity criterion set out by HiNES (1960), and may be the result of the semidiurnal tide.

\section{COMPARISON CASE II: AN EVANESCENT WAVE}

As already mentioned and listed in Table 3, one of the nine nights of quasi-monochromatic wave activity found in the MORTI data was the 4/5 May evanescent wave event. The MORTI full-ring average column emission rate, plotted in Fig. 7, has a cleanly sinusoidal appearance, owing to the evanescent mode having an amplitude 4.5 times as large as that of the accompanying internal mode. Segment analysis produced a period of $106 \mathrm{~min}$ and a horizontal velocity of $282 \mathrm{~m} / \mathrm{s}$ directed toward $32 \mathrm{~N}$ of $\mathrm{W}$ for the dominant mode, and use of the dispersion relation led to an imaginary vertical wavelength, signifying evanescence. In these calculations the Doppler effect was neglected because the green line wind measurements of BIRD et al. (1993) showed them to vary within $\pm 10 \%$ of the wave speed and hence to be of small importance. The MORTI full-ring rotational temperature is also plotted for the night in Fig. 7. The second crest, at 0400 , is precisely in phase with the corresponding emission rate peak, a characteristic of evanescent waves according to TARASICK and HINES (1990).

Comparison data from other sensors are shown in Fig. 8, including the Arecibo GL, the MORTI $\mathrm{O}_{2}$ and the Michigan $\mathrm{OH}$. Since the latter two represent the same location, it is especially interesting to note that the first crest in both traces occurs at the same time, although the second pair differ by about $12 \mathrm{~min}$. In fact the $\mathrm{OH}$ may match the Arecibo GL trace better than that of the MORTI $\mathrm{O}_{2}$ in the second crest but not in the first. These complications are again attributed to the presence of the internal wave with shorter period (see Table 3) passing overhead at the same time and the wave front not being plane. With these reservations, it is fair to say that the main outlines of all three traces are approximately aligned as if the waves had no vertical propagation velocity, another characteristic of an evanescent wave.

\section{CONCLUSION}

The $\mathrm{O}_{2}$ atmospheric (0-1) airglow column emission rate sampled over twelve segments of the annular field of view of MORTI was used in this study to determine the kinematic characteristics of gravity waves in the
90-100 km region during the April and May portions of the AIDA ' 89 campaign. Nine nights were found on which the wave activity could be described mostly by one or two spectral components with periods greater than $45 \mathrm{~min}$, and these were tabulated in Table 3. Because of the large volume of data available from the ground-based optical participants in AIDA '89, only two of these nights were selected for additional multi-station and multi-sensor comparisons. The first of these was the post-midnight period of $5 / 6$ April, a case of a dominant internal travelling wave observed by the maximum number of sensors. The second was the post-midnight period of 4/5 May, the only case found, at the time of writing, from the AIDA ' 89 campaign by MORTI to be best described by a dominant evanescent wave.

The comparisons included four airglow layers, three viewed locations, and eight sensors operated by five institutions at two ground stations. Under these conditions a full-fledged correlation study with a proper error analysis was not possible. Instead, visual similarity between different traces in similar graphical format was used to estimate phase differences. The difficulties introduced by each layer and location exhibiting its own set of high frequency components were severe, but in the two cases studied, consistency with the MORTI characterization was found in the related data. The patterns for the same airglow species from different points of view were remarkably similar, and speeds computed from phase differences between patterns from spatially separate sources were within a factor of two of those expected from the MORTI analysis. Data comparisons for different airglow layers are less easily malched, evidently because higher frequency components with short coherence distances complicate the patterns differently at different heights. In view of the agreement demonstrated here, we submit the summaries of Tables 3 and 4 as the currently most comprehensive and reliable description of longperiod gravity wave activity available from the optical instrumentation assembled at AIDA 89.

The comparison study of the internal wave of $5 / 6$ April provided additional information not available from the MORTI characterization. It showed the vertical sense of the wave propagation to be downward, indicative of a wave with origins in the lower atmosphere. It also showed trends during the night that suggested an internal wave of period longer than the data set. The comparison study of the reportedly evanescent wave of 4/5 May confirmed its evanescence. The result that only one night out of the nine (the night of highest $K_{p}$ ) for which the quasi-monochromatic condition seemed to apply demonstrated evanescence suggests that although some evanescent waves do 


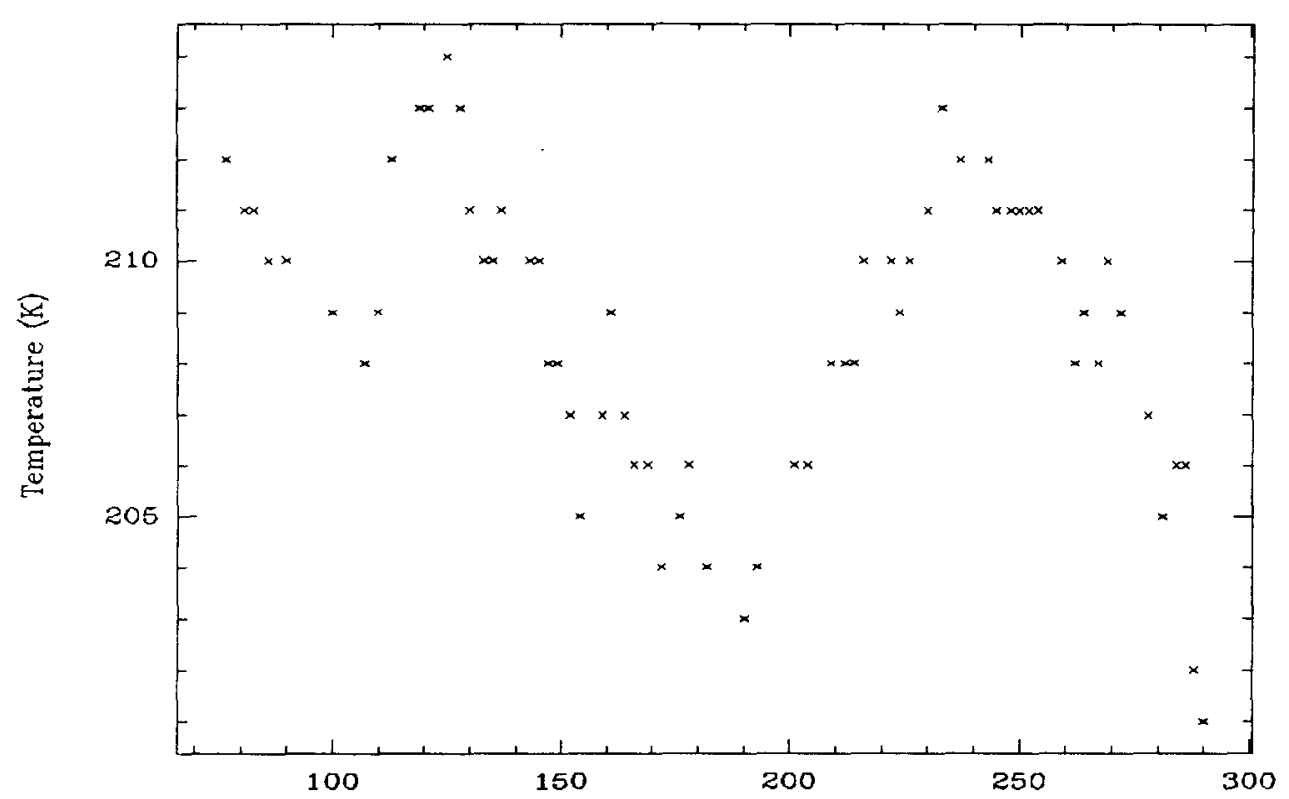

Local Time (minutes) from midnight, May 4/5, 1989

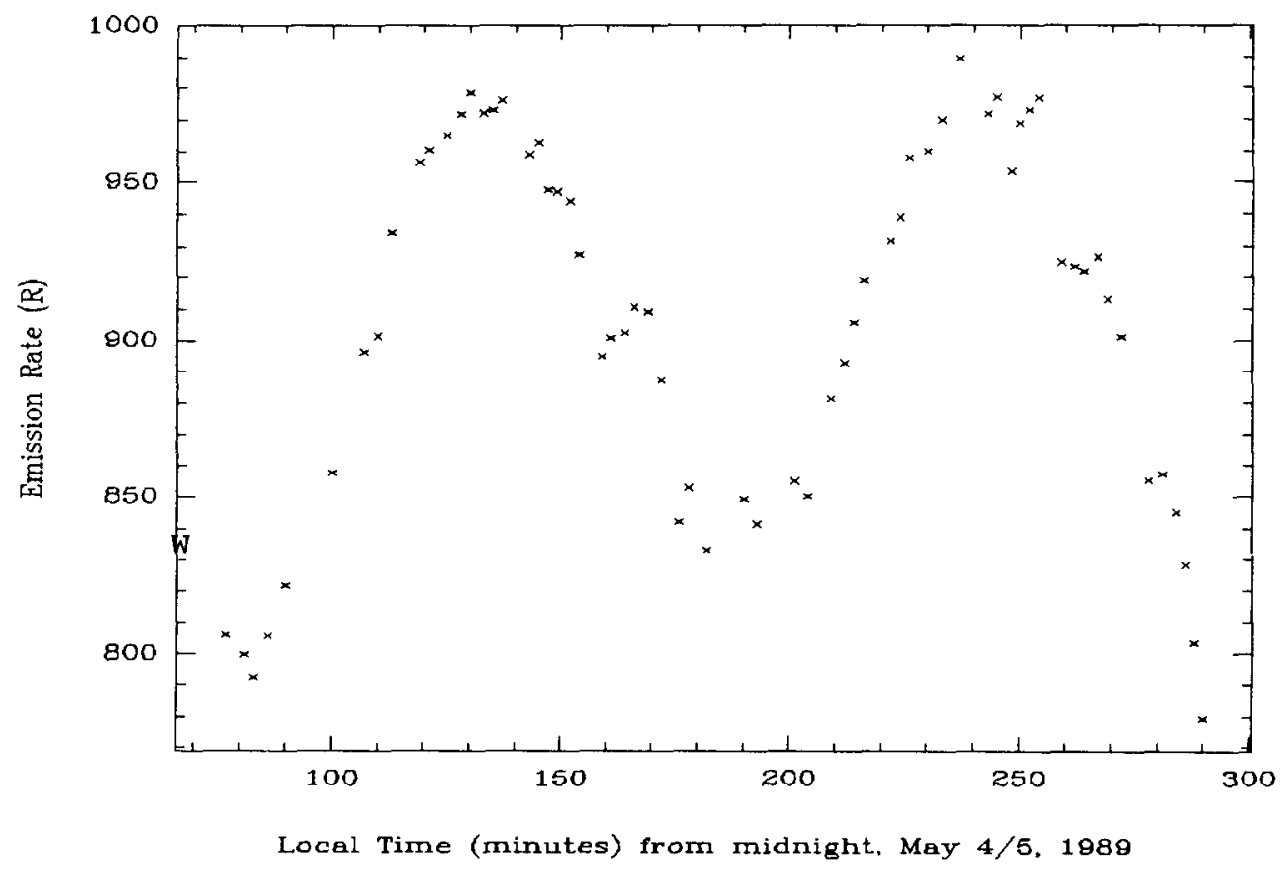

Fig. 7. Comparison plots of MORTI $\mathrm{O}_{2}$ column emission rate and rotational temperature sequences for an evanescent wave, 4/5 May 1989 , over Puerto Rico. 


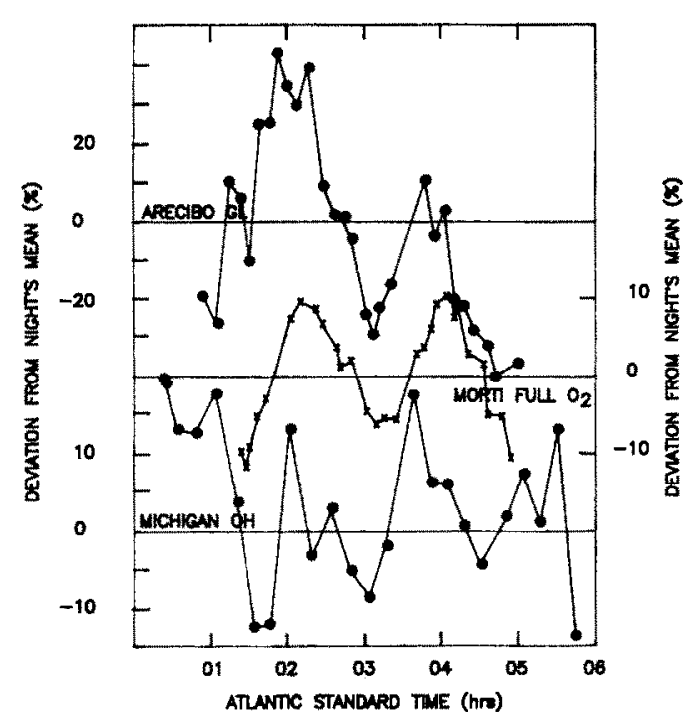

Fig. 8. Comparison plots of $\mathrm{OH}, \mathrm{O}_{2}$, and green line column emission rates for the evanescent wave of 4/5 May 1989. over Puerto Rico.

appear, they are probably not as common as internal waves in the $\mathrm{O}_{2}$ layer, at least for periods greater than $45 \mathrm{~min}$ and at low latitudes.

The present multi-station, multi-sensor study strengthens the assumption that the fluctuations in airglow emission rates are attributable to gravity waves. However, one might ask whether such luctuations are merely fluctuations of the transmittance of the lower atmosphere, clouds, that is, and have nothing to do with the airglow itself. While it is obvious that the observer must always bear this possibility in mind, the observations used here rule out the likelihood of this being an important effect. The simultaneous observation of two airglow species from the same location in the same direction gives different traces, as in Fig. 5 ; the simultaneous observation of the same species at the same point from two different locations gives the same pattern, as in Fig. 3. Furthermore all observers diligently attended their instruments throughout the campaign and looked for darkenings of the star field or any other indicators of cloud.

Acknowledgements - The Institute for Space and Terrestrial Science is a designated Centre of Excellence supported by the Province of Ontario's Technology Fund. S. P. Zhang was supported by a grant from NSERC of Canada, J. H. Hecht in part by NSF grants ATM-90-00216 and ATM-88-11771, R. Niciejewski by NSF grant ATM-8901367, and L. Kieffaber by NSF grants ATM-8823067 and ATM- 8800026 and a travel grant from Arecibo Observatory. The Arecibo Observatory is operated by Cornell University under a cooperative agreement with the National Science Foundation.
Bird J. C., Tepley C. A. and Shepherd G. G.

Hecht J. H., Kane. T. J., Walterscheid R. L., Gardntr C. S. and Tepley C. A.

HINES C. $\mathrm{O}$.

Press W. H. and Teukolsky S. A.

Takahashi H. Sahai Y. and Texeira N. R.

Takasick D. W. and Hines C. $O$.

Tarasick D. W. and Shepherd G. G.

VIERECK R. A.

Viereck R. A. and DeeHr C. S.

Wiens R. H., Zhang S. P., Peterson R. N. and SHEPHERD $G, G$.

Zhang S. P., Peterson R. N., Wiens R. H. and Shepherd $G, G$.

\section{REFERENCES}

1993 Optical measurements of neutral winds durin AIDA $_{5}$ "89. J. atmos. terr. Phys. 55, 313.

1993 Simultaneous nightglow and lidar observations at Arecibo during the AIDA 89 campaign. I. atmos. terr. Phys. 55, 409 .

1960 Internal atmospheric gravity waves at ionospheric heights. Can. J. Phys. 38, 1441

1988 Search algorithm for weak periodic signals in unevenly spaced data. Comp. Phys. 2, 77.

1990 Airglow intensity and temperature response to atmospheric wave propagation in the mesopause region. Adv. Space Res. 10, 77.

1990 The observable effects of gravity waves on airglow emissions. Planet. Space Sci. 38, 1105.

1992 The effects of gravity waves on complex airglow chemistries $\mathrm{I}: \mathrm{O}_{2}\left(b^{\prime} \Sigma_{y}^{+}\right)$emission. J. geophys. Res. 97, 3185.

1991 A review of mesospheric dynamics and chemistry, Rev. Geophys. Supplement, U.S. National Report, 1132.

1989 On the interaction between gravity waves and the $\mathrm{OH}$ Meinel (6-2) and the $\mathrm{O}_{2}$ atmospheric $(0-1)$ bands in the polar night airglow. $J$.geophys. Res. 94, 5397.

1991 MORTI : a mesopause oxygen rotational temperature imager. Planet. Space Sci. 39, 1363.

1993 Gravity waves from $\mathrm{O}_{2}$ nightglow during the AIDA '89 campaign 1 : emission rate/temperature observations. J. atmos. terr. Phys. 55, 355. 